\title{
Long-lasting Antimicrobial Effect Achieved via Immobilization of Antimicrobial Agents on Hair Shaft
}

\author{
Jong il Kim ${ }^{1}$ and Seong kil Son ${ }^{2 *}$ \\ ${ }^{1} S \& R A$ Center, LG Household \& Health Care, Korea \\ ${ }^{2} H G$.RP. HDR. Project, LG Household \& Health Care, Korea
}

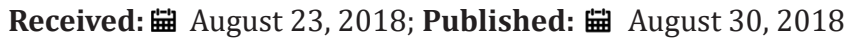

*Corresponding author: Seong kil Son, Principal Researcher of HGRP HDR Project, LG Household \& Health Care, Daejeon, Korea

\begin{abstract}
Dandruff and underarm malodor are caused by microorganisms. Personal hygiene products containing various types of antimicrobial agents are used to relieve this condition, but the effect is not long-lasting. In this study, we tried to maintain the antimicrobial effect for a long time by covalently binding the antimicrobial component to the hair shaft. Antimicrobial activity against dandruff strains, underarm malodor associated bacteria, and skin microbial strains were evaluated using hair fixed with antimicrobial agents. The hair shaft covalently bonded of the QAC showed antibacterial activity against all tested bacteria. Although the antibacterial effect was slightly decreased after 5 washes, it was confirmed that the antibacterial effect still remained. The results of this study may be applied to personal hygiene products such as shampoos and deodorants that act as antimicrobial agents to prevent and alleviate dandruff and axillary odor.
\end{abstract}

Keywords: Hair; Antimicrobial Activity; Quaternary Ammonium Chloride; Dandruff; Underarm Malodor

\section{Introduction}

\section{Problem}

Dandruff is the most common scalp condition that is often accompanied by itching and erythema [1]. The complex causes of dandruff include excess sebum secretion from the sebaceous glands, hormonal imbalance, and excessive proliferation of Malassezia species in the scalp. The viable numbers of these yeasts reportedly increase 1.5-2-fold in numbers when dandruff is present [2]. These species degrade triglycerides in the sebum to produce oleic acid, which is absorbed into the stratum corneum. After absorption, oleic acid causes an inflammatory response in keratinocytes, which disrupts homeostasis, leading to the erratic cleavage of keratinocytes, and ultimately to dandruff [3]. Underarm malodor is caused by the degradation of secreted milky odorless liquid consisting of electrolytes, steroids, proteins, and lipids from the apocrine glands onto the skin surface by the gram-positive bacteria Corynebacterium xerosis and C. jeikeium, which reside on the skin surface [4-7]. The bacterial biotransformation produces 3-methyl-3-sulfanylhexan-1-ol, 3-sulfanylhexan-1-ol, 3-methyl3-hydroxy hexanoic acid, $5 \alpha$-androst-16-en-3, isovaleric acid, and propionic acid [8-10], which are typical sources of malodor. Typically, in non-severe cases of dandruff and underarm malodor, over-the-counter personal hygiene products are used. However, personal hygiene products used for the prevention and alleviation of symptoms are washed off from the body due to sweating and washing after use. Due to this reason, it is difficult to expect the persistence of antimicrobial effects and the products are used every day, which can irritate and sensitize the skin [11]. A novel approach is desirable.

\section{Problem Solving Strategies}

The scalp and armpit regions are typically replete with hair. Disulfide bonds in the hair keratin are reduced to cysteine by external environmental factors, including chemical treatment of hair and ultraviolet radiation [12]. Cysteine accounts for approximately $14 \%$ of all amino acids in hair keratin. Moreover, hair in the scalp and underarm is near skin that is colonized by microorganisms responsible for dandruff and underarm malodor. This suggests a strategy, in which the appropriate antimicrobial agents are immobilized onto cysteine residues in hair keratin, where they would be readily available to kill the offending microorganisms. This strategy has merit, given that absorption, coating, and incorporation are often used to immobilize antimicrobial ingredients onto wool, hair, and fabrics. However, the antimicrobial effects often do not persist [13-15].

\section{Strategy Tactics}

In the present study, we immobilized an antimicrobial agent to cysteine thiol groups in hair keratin and evaluated the subsequent antimicrobial effects. In this approach, hair was first treated with thioglycolic acid, which served as a reducing agent to disrupt disulfide bonds in hair and reduce them to cysteine. The cysteine 
residues could then form covalent bonds with the antimicrobial agent. Next, through a thiol-ene reaction among [2-(acryloyloxy) ethyl] trimethylammonium chloride, an acrylate monomer containing QAC, and cysteine thiol groups, QAC was immobilized via covalent bonding onto the hair surface. QAC immobilization was confirmed through Fourier-transform infrared spectroscopy. The antimicrobial effects against six microorganisms that typically cause dandruff and underarm malodor were evaluated.

\section{Result}

The hair shaft covalently bonded of the QAC showed antibacterial activity against all tested bacteria. Although the antibacterial effect was slightly decreased after 5 washes, it was confirmed that the antibacterial effect still remained.

\section{Conclusion}

This report may provide for the first time the results of a study using human hair as a carrier for antimicrobial treatments. Based on these findings, we suggest that the method could potentially replace personal hygiene products, such as shampoos and antiperspirants, that act as antimicrobial agents for the prevention and alleviation of dandruff and underarm malodor. Furthermore, such products are for daily rather than for one-time usage. However, repetitive usage of these products may provide an accumulative effect. The findings may be useful for the alleviation of underarm malodor, since the hair there is in frequent contact with skin that harbors microorganisms causing such malodor.

\section{References}

1. Rapini RP, Bolognia JL, Jorizzo JL (2007) Dermatology: 2-volume set Elsevier Science Publishers New York, USA p. 2776.

2. Ranganathan S, Mukhopadhyay $T$ (2010) Dandruff: the most commercially exploited skin disease. Indian J Dermatol 55(2): 130-134.

3. Dawson TL (2006) Malassezia and seborrheic dermatitis: etiology and treatment. J Cosmetic Science 57(2): 181-182.
4. Labows JN, Preti G, Hoelzle E, Leyden J, Kligman A, et al. (1979) Steroid analysis of human apocrine secretion. Steroids 34: 249-258.

5. Leyden JJ, McGinley KJ, Hoelzle E, Labows JN, Kligman AM, et al. (1981) The microbiology of the human axilla and its relationship to axillary odor. J Invest Dermatol 77: 413-416.

6. Stefaniak AB, Harvey CJ, Wertz PW (2010) Formulation and stability of a novel artificial sebum under conditions of storage and use. Int J Cosmetic Science 32: 347-355.

7. Noël F, Pierard-Franchimont C, Pierard GE, Quatresooz P (2012) Sweaty skin, background and assessments. Int J Dermatol 51: 647-655.

8. Zeng X-N, Leyden JJ, Lawley HJ, Sawano K, Nohara I, Preti G, et al. (1991) Analysis of characteristic odors from human male axillae. J Chem Ecol 17: 1469-1492.

9. Natsch A, Derrer S, Flachsmann F, Schmid J (2006) A broad diversity of volatile carboxylic acids, released by a bacterial aminoacylase from axilla secretions, as candidate molecules for the determination of human-body odor type. Chem Biodivers 3:1-20.

10. Troccaz M, Borchard G, Vuilleumier C, Raviot-Derrien S, Niclass Y, et al. (2009) Gender-specific differences between the concentrations of nonvolatile $(\mathrm{R}) /(\mathrm{S})$-3-methyl-3-sulfanylhexan-1-ol and $(\mathrm{R}) /(\mathrm{S})-3$ hydroxy-3-methyl-hexanoic acid odor precursors in axillary secretions. Chem Senses 34: 203-210.

11. Jamie R, Leonel-Maximo M, Ananthapadmanabhan KP (2013) Novel glycinate-based body wash: Clinical investigation into ultra-mildness, effective conditioning, and improved consumer benefits. J Clin Aesthet Dermatol 6(6): 23-30.

12. Célia F, Cristiana C, Andreia C, Teresa M, Artur Cavaco-Paulo, et al. (2016) Human hair and the impact of cosmetic procedures: A review on cleansing and shape-modulating cosmetics. Cosmetics 3(3): 26-47.

13. Simoncic, B, Tomsic B (2010) Structures of novel antimicrobial agents for textiles. Text Res J 80: 1721-1737.

14. Dickerson MB, Sierra AA, Bedford NM, Lyon WJ, Gruner WE, et al. (2013) Keratin-based antimicrobial textiles, films, and nanofibers. J Mater Chem B 40: 5505-5514.

15. Dan Yu, Jackie YC, Xin L, Jeffrey SC, Lijing W, et al. (2014) Novel immobilization of a quaternary ammonium moiety on keratinfibers for medical applications. Int J Biol Macro 70: 234-240.
ISSN: 2574-1241

DOI: $10.26717 /$ BJSTR.2018.08.001666

Seong kil Son. Biomed J Sci \& Tech Res

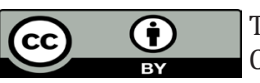

This work is licensed under Creative Commons Attribution 4.0 License

Submission Link: https://biomedres.us/submit-manuscript.php

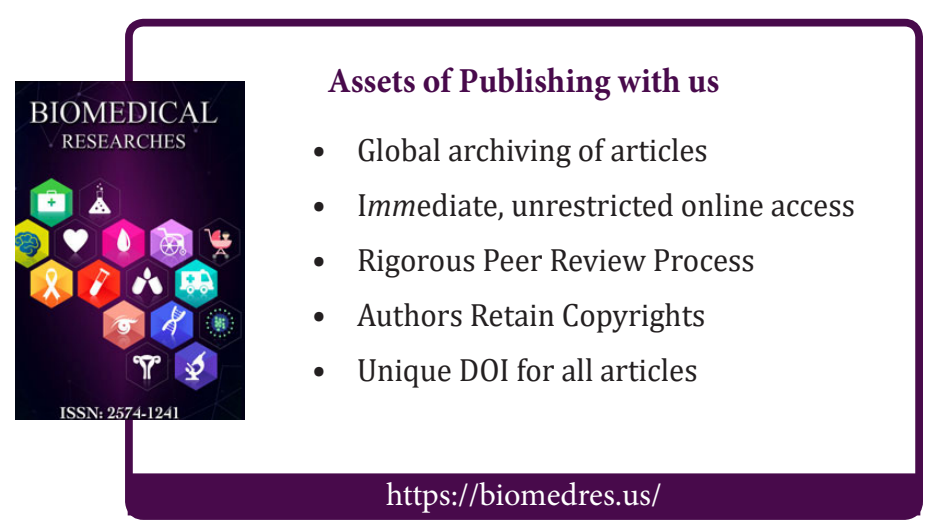

